\title{
Dendrochronology Study of Culture Black Pine (Lat. Pinus Nigra) in Area Šumadija (Serbia)
}

\author{
Severin, Šikanja \\ Singidunum university-Belgrade \\ Faculty for applied ecology Futura
}

\begin{abstract}
This paper analyzes the importance of monitoring dendrochronology study as indication aspects of the vitality of trees, pine and general culture of pine. The task was processed on the basis of a detailed analysis of black pine trees in the field and study of numerous bibliography in these areas. Dendrochronology study basis of monitoring and diameter increment, and the monitoring all the elements of volume increment. Research has been conducted on the territory of Šumadija, in the area of forest estates of Kragujevac. The monitoring it self is very important both because bioindicative, and future culture management of pine.
\end{abstract}

Keywords: increment, monitoring, dendrochronology.

\section{Introduction}

The vitality of forests and trends of their race, today the basic settings that determine the level and nature of economic activity in forestry, but also need special social care and prescribing measures to restrict all forms used when necessary. Observing the responses of individual species to change environmental conditions (climate change, temperature extremes, air pollution, groundwater level) represent elementary task in the process of preserving forests, as this does not happen actually, or if quantitative indicators are proven. Research integrates ecological and dendrochronological methods to investigate the extent of natural and anthropogenic impacts on declining whitebark pine communities in Šumadija- region- Serbia.

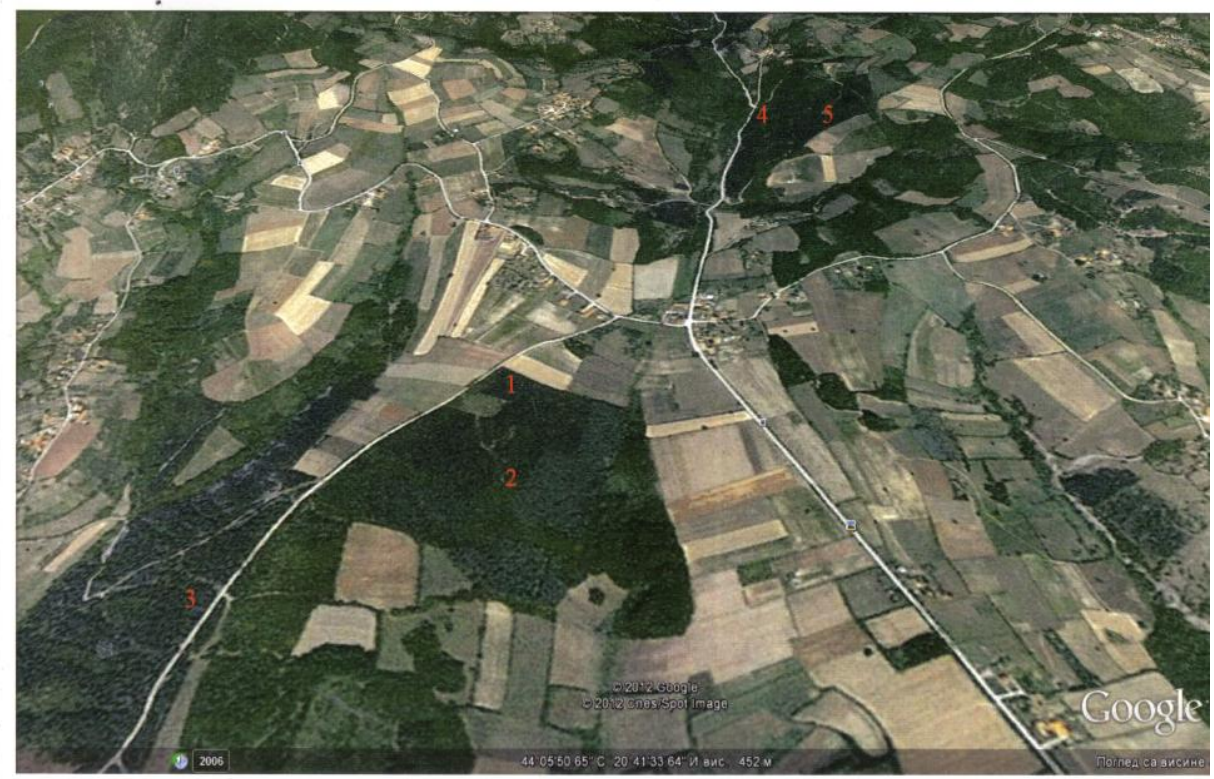

Figure: no. 1 (Study area)

\section{Material And Methods}

The study was conducted on sample surfaces in the cultures of black pine, in the area of Šumadija. Experimental fields are separated according to the methodology of forestry (Banković, 1995). It was determined that the tracking of black pine, and very experimental fields located in Woodlands, GružanskoLepenički-Jaseničke-Forests, since this management unit includes a great number of the black pine culture. Geological base pertain ferruginous sandstone-quartz-decaying department $65 \mathrm{~g}$, 65d and 65a, and serpentinite, mostly in the wards 66a and 66b. (5 experimental field)- Figure 1. Plots are contain eutric brown soil, in the first three wards in two others the eutric siliceous soil. 
Elevation ranges from $350 \mathrm{~m}$ to almost $500 \mathrm{~m}$ above sea level which does not stand as a big range, and therefore does not have any big influence on the state of the crops. The slope of the terrain ranges from 5 to 15 degrees, which as a steep medium is exposure prevailingly to northwest and southwest.

Concerning air study of the area, it is quite continental to moderately continental. Climatic conditions differ depending on the altitude, relief and exposure with the average annual temperature is $11.4^{\circ} \mathrm{C}$., the period without frost of between 180-215 days and the period of sunshine of 2100 hours per year. The maximum and minimum temperatures ranged in their absolute amount of $41.7^{\circ} \mathrm{C}-\left(-37^{\circ} \mathrm{C}\right)$. It can be concluded that there are large fluctuations in temperature, where the hottest months are July and August, and the coldest January and February.

Furthermore, average annual rainfall is $819,8 \mathrm{~mm}$, and since the winds are the most northern squally wind. The snow and wind have negative effects and fractures in cultures are noticeable as it is well known that black pine has deep roots and resistant to rippings by the wind, which is not the case with heavy snowfalls and strong winds.

In order to study floristic composition and phytosociological determination of belonging study stands, phytocoenologically captured at all sample plots obtained by the method of Braun-Blanquet's. Detailed research has revealed that artificially established Austrian pine (Pinus nigra Arn.) Are on farneto oak-cerris Quercetum farnetto Rud.1949.This community belongs to the class syntaxonomic terms Querco- Fagetea Br.-Bl.et Vliegen 1937, right-Quercetalia pubescentis No.Bl.1932, regarding Quercion farnetto Ht.1954. In all experimental fields is done the following: entire dendrometric diameter mesured, diameter, height, drill punched the tree, for taking increment cores and computation of gain, by Presler method. On the basis of the data, the volume and growth were calculated and measurements and analysis of growth rings were performed in the laboratory, by special instruments and related software. (Digital positionmetre, TSAP, statistical analysis, etc.). Observing the action of both endogenous and exogenous factors was conducted, supporting on the state of the stand and directly, based on quantitative and qualitative characteristics of volume increment. Monitoring the situation stands, covers, mostly components that are related to stand structure and which, together with the analysis increments allow for a realistic assessment of the current situation and future forecast development.

\section{Results}

The elements of stand structure (diameter, height, crown development, biological position of the trees), and in particular the volume and diameter structure, showing that the stand is in a phase of strong regressive succession. Pine, as pioneer species, has a relatively strong impact if included the land, the ground flora, microclimate, vegetation, stand aging and site conditions. Black pine is known as a species that can regenerate its growing force, regardless a greatly suffering and damage that can suffer, so in case of favorable conditions, it can be manifested in diameter and volume increment a lot. ( Figure 2)-diameter incremenet. This the stand is dominated by species of lower production, namely lower ecological.

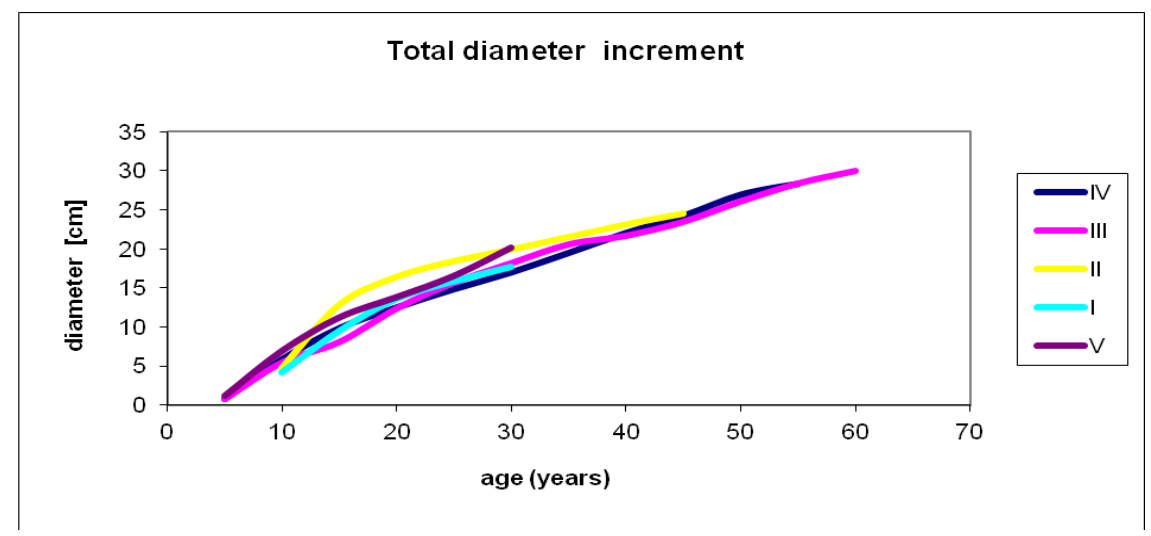

Figure 2. (Total diameter increment for 5 experimental field.)

In Figure 2. is shown the growth of trees in thickness, shown is actually the total diameter increment for all five analyzed trees, for all five experimental fields, growth curves, show actually known flow, growth and development of trees in thickness, and there are no major discrepancies. If you take a closer look at the graph, we see that in II tree analysis, ie. in another experimental field, that values a little higher in the second relationship to the tree analysis, the reason is because they are in the experimental field made care measures, thinning, about 2o-year of age. All other curves are more or less similar to the flow. First culmination of gain was between the 10 and 15 years of age. Growth curves would have a different course that made care measuresin another experimental field, that values a little higher. 

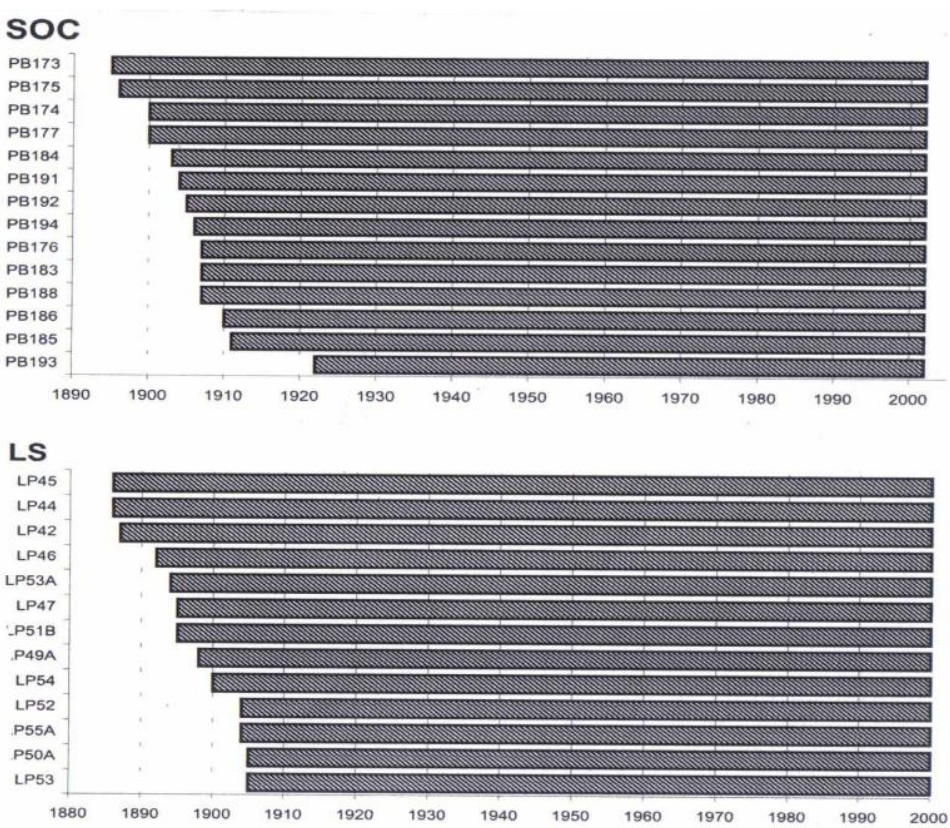

Figure 3. (Spans of individual series of the radial of Pinus Nigra, (SOS) and (LS)

Explanation: Chronology SOS displays high similarity of individual dendrograms, as well as high number of signature (29 years, 10 positive and 19 negative). The chronology LS contains 10 positive years, but only 8 negative ones, altogether 18 signatures.

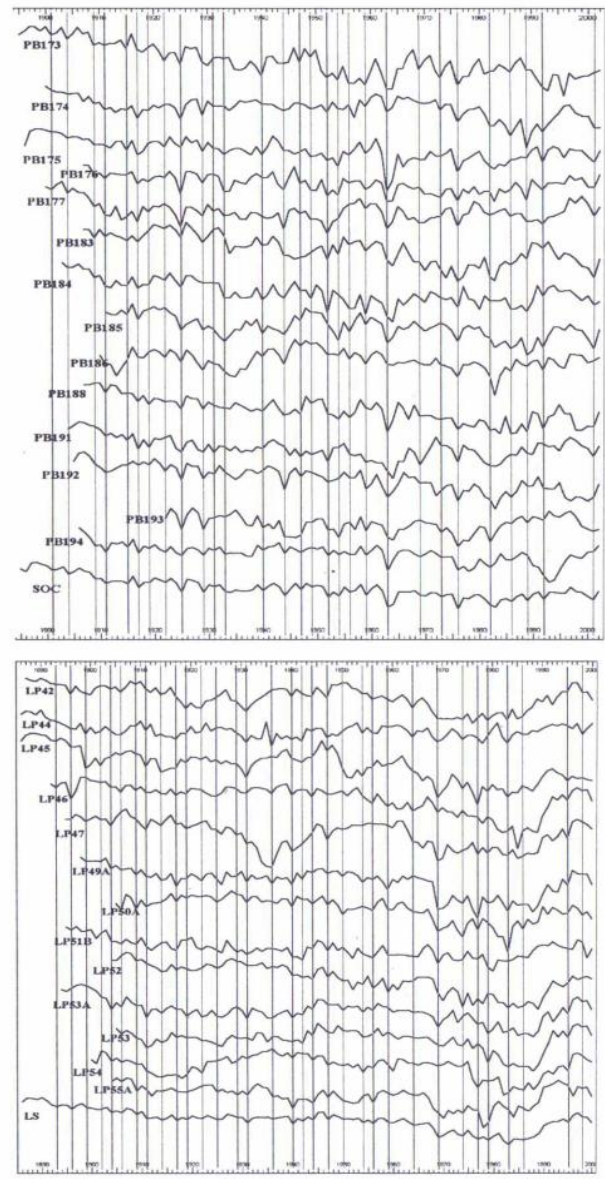

Figure 4.(Dendrochronological patterns of Pinus Nigra) This is Figure 4, in in connection with Figure 2. It is the diameter increment, with the difference being that in Figure 2, showing s gross-total diameter increment, and here- in Figure 5 shows each oscillation diameter increments. 

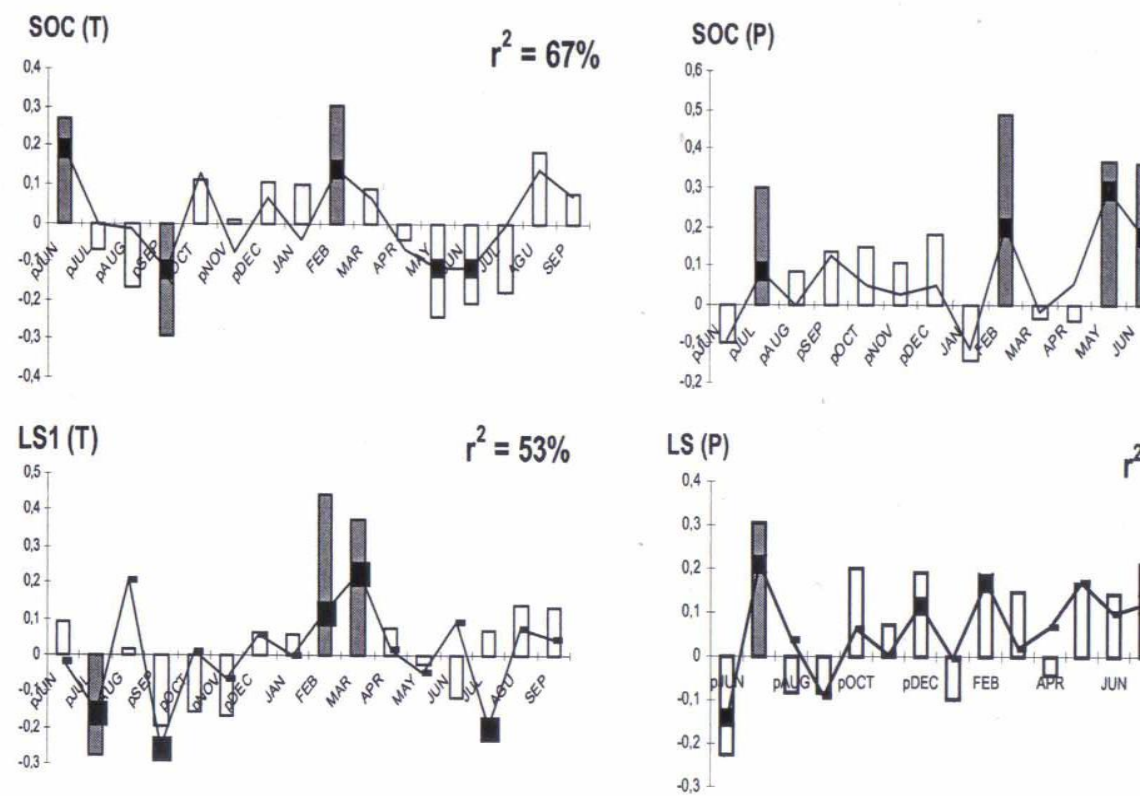

Figure 5.: Results of the response function analysis and coleration coefficients for $(\mathrm{T})$ Temperature and rainfall

(P)...simple correlation- bars regression coefficients-lines.

Values statistically significant for ----- = 0,05- gray bars, and black squares, SOS- Pinus Nigra, LS- Pinus sylvestris.

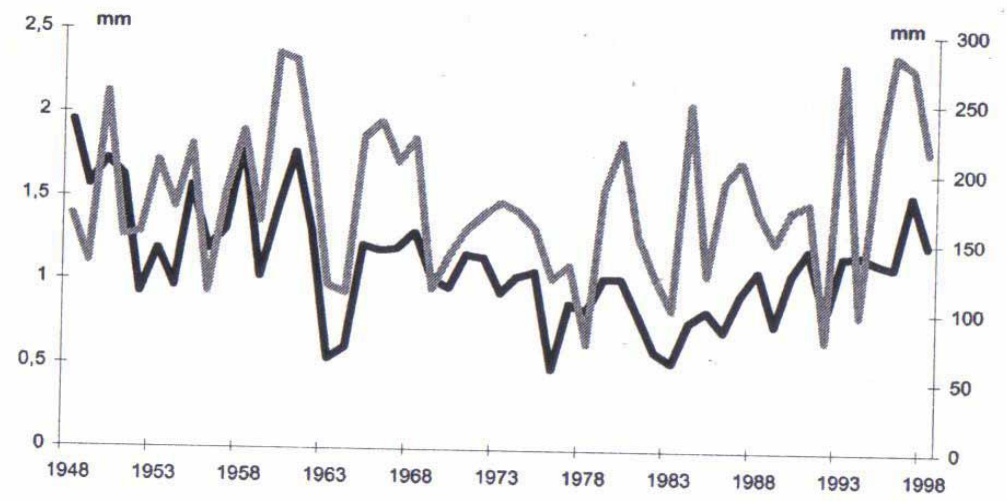

Figure 6: Similarity between tree ring width chronology of the Pinus Nigra, (black) and amount of May July rainfall ( gray).

Dendrochronology of black pine trees and the character of its reactions to exogenous factors are checked by volume and the radial increment, ie the width of the growth ring (Ir). In addition to the width of tree rings as a significant productioning indicators, the analysis of variation in the width of tree rings from wide to very narrow is of particular importance, as bio-indicators of vulnerability of a species in a given habitat. (Mihajlov 1962 ). In addition to the oscillation, the width of tree rings is very important indicator of the trend of growth.

Special analysis included first biological position of black pine trees, whose growth is not affected by competitors, butresults from tree vitality and activity of exogenous factors. (Figure 7) It is characteristic that the tree ring width varies in a wide range of only $0.5 \mathrm{~mm}$ (which is not typical for the tree and biological position), to more than $3.5 \mathrm{~mm}$. Also, there is a clear tendency of decreasing of diameter increment past ten years. The trees with a bit width of tree rings do not have sufficient capacity to carry water and nutrients, which in the case of dominant trees, due to the development of the crown and large transport distance, often leads to disbalance between supply and consumption of water or to revitalization and death. 


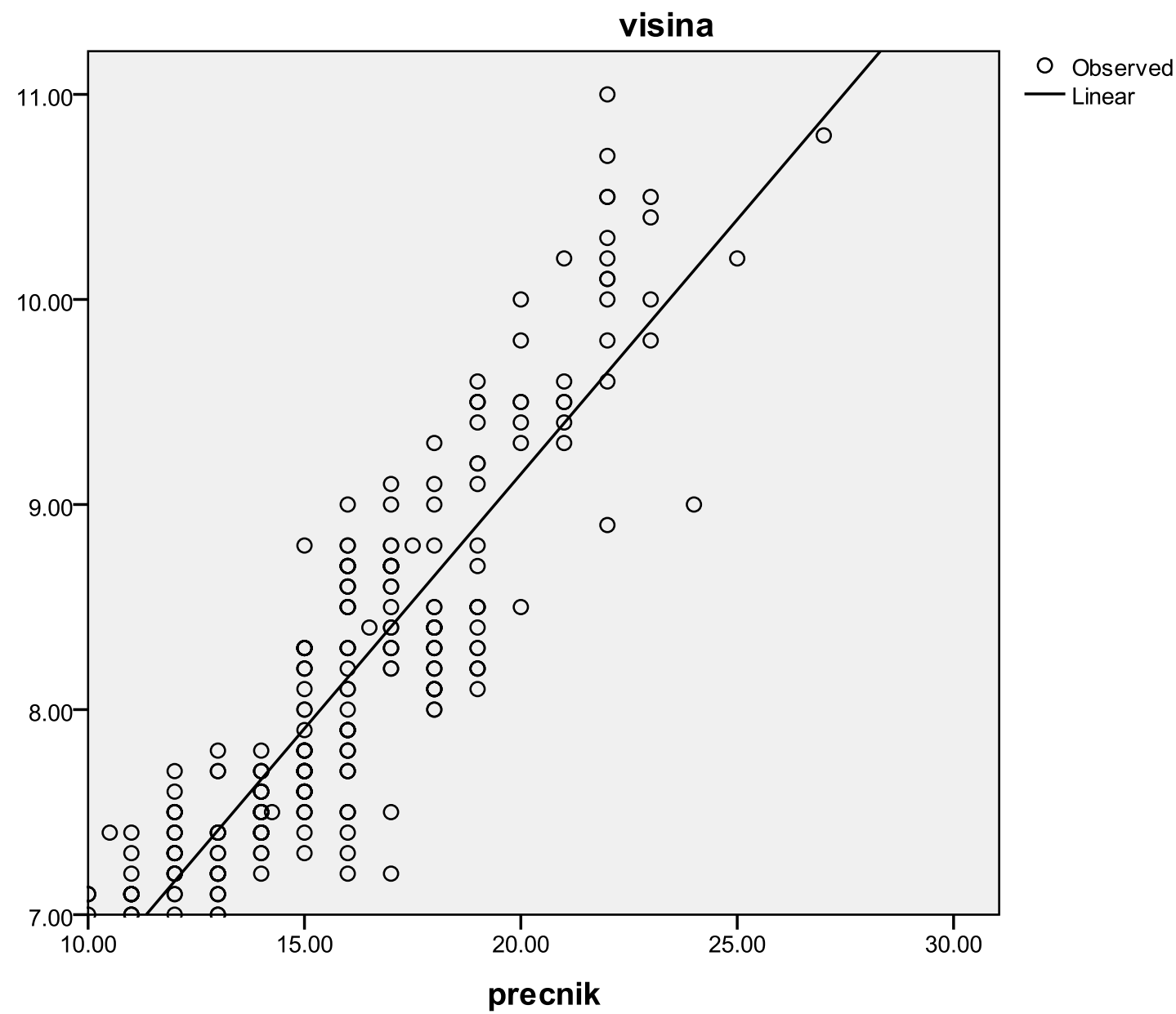

Figure 7. Special analysis of dendrochronology, included first biological position of black pine trees, whose growth is not affected by competitors, but results from tree vitality and activity of exogenous factors.

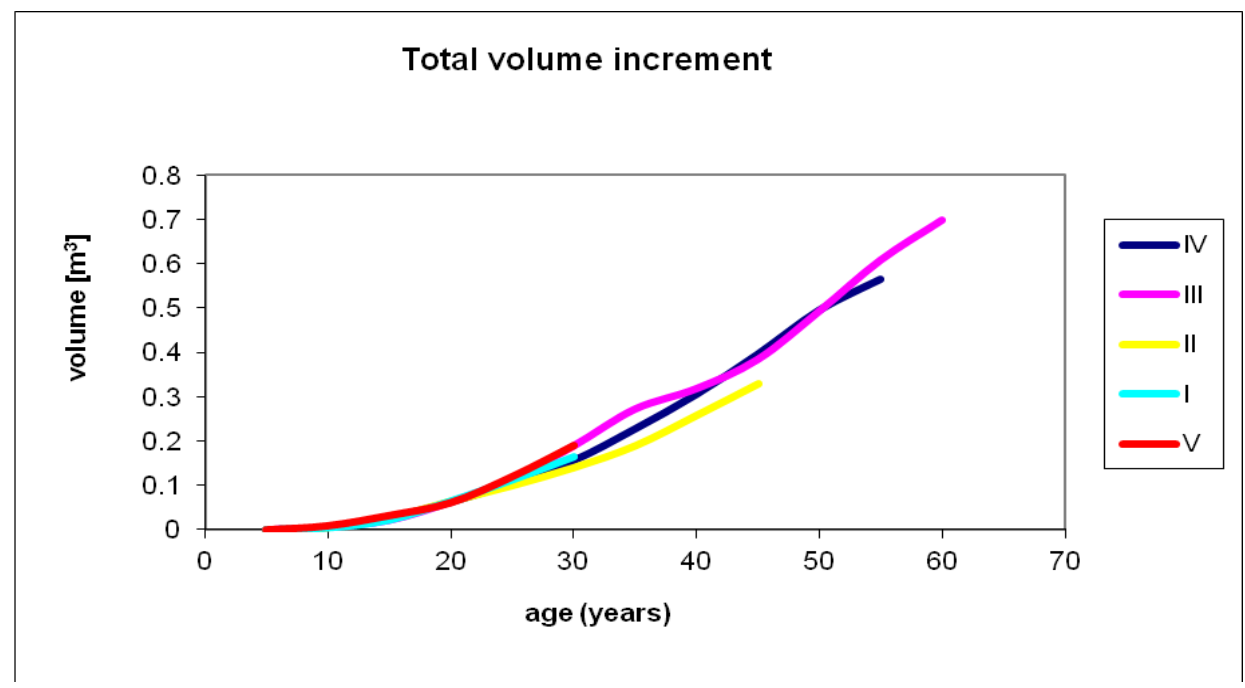

Figure. 8. (Total volume increment for 5 experimental field)

In Figure 8. is shown the volume of the growth of trees, which actually means the total volume growth of trees throughout the life. The volume growth of trees has a normal consequence, diameter and height increment and streams increment, of all five analyzed trees, have more or less similar to the current value of that 
volume growth during the life of the trees. Only a small, insignificant little, expressed the value of the code, II analyzed trees around 30 years of age.

A

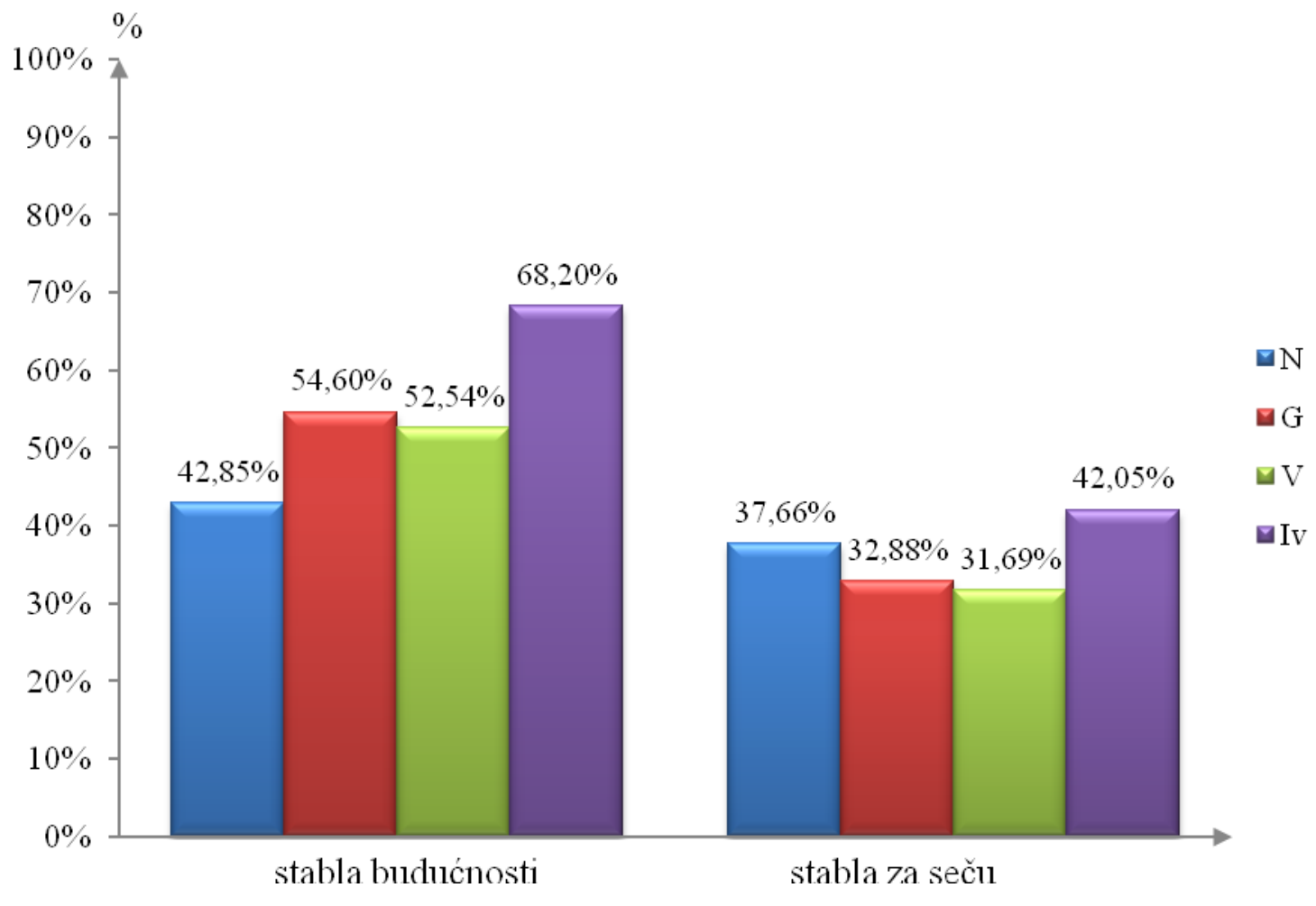

Figure 9.

On the Figure 9, the average line width index of vital years $(\mathrm{A})$ and trees with hidden devitalisation symptoms are shown (B). Characteristic of the tree reduced the vitality to the entire interval of observation have a width index years, less than -1 which is a clear sign of the lost ability to increase gain in the vegetation period and with extremely favorable conditions for the formation of growth rings.

One of method dendrohronology explains the observed process of dying and reducing the number of black pine trees, pointing to further adverse development courses that can be expected in the case of abandonment of the stand with spontaneous development and applying natural laws. The most widely about conceding stand spontaneous development can speak only conditionally, since the character of their further development aimed at previous usage (stands thrown out of balance), or are strongly influenced by global and local changes in environmental conditions, very often both expressed through synergistic effect.

If beech and oak stands were considered economically less valuable, as it is sometimes present in practice, it could be through the seemingly spontaneous evolutional process at first sight, justified and expressed in protective and ecological function of forests, particularly in buildings of special purpose, such as national parks. Yet, if the protective and ecological potential noise produced is proportional to the organic matter is included, then the justification must be seriously questioned, neglecting the care of their composition by tree species, and the level of production of organic matter. It is known that they represent extremely important ecological functions of forests, such as reducing the concentration of $\mathrm{CO} 2$ in the air and forming the oxygen, directly related to the balance of assimilation of the volume increment.

\section{Conclusion And Discuss}

Conducted research and analysis show that there are many strong reasons for monitoring the vitality of forests, and forecast their future development. Monitoring activities should be complex and constant, whereby it is necessary to include the typical natural and businesses, especially those that are already indication, tending to distort the natural balance and revitalization. 
The knowledge of the need for ongoing security stability of forest ecosystems, and thus and existential basis of Forestry, indicate the need for in-depth research and monitoring increment of forest trees as a complex reaction trees on stimulating and disruptive action of exogenous and endogenous factors.Advocating for experienced, well-established procedures and schemata in forest management, as the basis of rational forestry, it must be replaced by the new active approach, directed towards learning from nature, and supporting only those natural processes ,acceptable for a man. This leads to a better implementation of environmental ethics, and the boundaries between classical forestry and applied ecology. Such an approach is void if not improving considerably more complex and expensive system of forest management used only in the event that there is a material base. Arguing for a concept close to nature forest management, it is frequently the sphere of economic realism, uncritically and without valid arguments becomes environmentally romanticism, which rests on a claim-Nature knows best. It is the last resort for resolving all issues related to forest forests. In doing so, they lose sight of some important facts:

-- Nature do not always act rationally and is not always directed towards the positive direction of movement,to preserve stability, particularly when the individual anthropogenic activities important part is moved out of balance.

-- In the centre of all events is the man who must solve their existential question in order to survive

- Letting a forest to a spontaneous development-without proper supervision, a man of action, leading to a drastic measures, by reducing their effectiveness in compaing numerous functions of forests.

- It is undoubtedly true, however, that modern human survival and development owed it ot the nature, which requires the assistance of the man itself.

-- In such circumstances, it is very important to avoid extremes and advocacy solutions that are not based on objective indicators. Orientation on short-term solutions only and relying on emotions could have devastating consequences for the forest, and nature in general.

-- Only rational use of forest and natural renewable resources, with controlled monitoring, can provide a secure future for forests and nature at all.

\section{Reference}

[1]. Banković S. 1995 Metodi i tehnika naučno istražvačkog rada, skripta, p 150, Beograd, 2, p:33-40

[2]. Barčić D, Španjol Ž, Rosavec R,-2010-Impact on site and development of black pine(Pinus Nigra Arn),forest cultures in the submediterannean, karst area-Croatian

[3]. Cedro, A. 2006. Comparative Dendroclimatological Studies of the Impact of Temperature and Rainfall on Pinus nigra Arnold and Pinus sylvestris in Northwestern Poland. Baltic Forestry, Vol:12 (1): 110-116.

[4]. Dolatowski J. Seneta W. 1997. Dendrologia (Dendrology). PWN, Warszawa: 62-63 ( Poland) Goor, A. Y., and C. W. Barney. 1976. Forest tree planting in and zones. Arnold Press, New York. 504 p.

[5]. Mihajlov I. -Matematičko formulisanje zakoninosti rastenja šumskog drveća-(1962)-zbornik radova-Skoplje

[6]. Nacionalna invetura šuma,Beograd.(2012)

[7]. Šumsko privredna osnova-Šumskog Gazdinstva Kragujevac (2010)

[8]. Tobolski, James J., and M. Thompson Conkle. (1977). Enzyme identification of Austrian x Japanese red pine hybrids in seed from mixed pollen controlled

[9]. Vitas A.(2008), Tree rings chronology of Scotc-pine, (Pinus Silvestris L.) for Lithuania, Baltic Forestry -14 Volume (2) p 110115 